\title{
Aftershock of a Vaccination Gap: The Measles Epidemics in Tirana, 2018
}

\author{
Dritan Ulqinaku ${ }^{1}$, Gentian Vyshka ${ }^{2 *}$ \\ ${ }^{1}$ Department of Chronic Diseases, Institute of Public Health, Tirana, Albania \\ ${ }^{2}$ Biomedical and Experimental Department, Faculty of Medicine, University of Medicine in Tirana, Albania
}

\begin{abstract}
Tirana, capital of Albania, has seen an acute increase in the measles cases during 2018, with a total figure surpassing 1000 of patients. The outbreak happened while the country was only witnessing very few and isolated cases for several years, as to have officially declared the disease as eradicated. Several reasons might have led to the outbreak of this epidemic, with a clear vaccination gap in the years 1997-1998. Authors discuss this under vaccination as well as other factors detectable in this group of patients, such as a peak in the first-year age infants and the prevalent distribution in the suburban area of the city, actually inhabited from a large number of internally migrated people.
\end{abstract}

KEYWORDS: Measles; Epidemics; Outbreak; Undervaccination

\section{INTRODUCTION}

The issue of reappearance of infectious disorders previously thought as eradicated is an old problem, challenging seriously health systems all over the world. When these infections reappear, from the public health point of view, we are generally dealing with outbreaks whose geographical extension might vary considerably.

A number of factors will contribute to outbreaks of infections considered as eradicated: once and again, silent, dormant and resistant foci will flare up. Imported cases coming from endemic areas will play an important role: we have discussed and reported cases of non-autochthonous malaria in Albania while the country has considered the disease as eradicated since several decennia [1].

Other concerning issues have been raised, always under the public health perspective, with regard to undervaccination or gaps in vaccination. Such might be the case with recent outbreaks of measles in disparate regions of the New and Old World. As a matter of fact, measles eradication has been challenged following continuous epidemics foci that erupt in disparate settings, both in time and geographic distribution. Albania's southern neighbouring country, Greece, has reported a measles outbreak in 2017-2018 [2]. It seemed not an isolated phenomenon, since almost at the same period of time other remote countries to our region were

\section{Vol No: 05, Issue: 01}

Received Date: May 28, 2021

Published Date: June 30, 2021

\section{*Corresponding Author}

\section{Gentian Vyshka}

Faculty of Medicine, University of Medicine in

Tirana, Albania, Tel: +355692828140;

E-mail: gvyshka@gmail.com

Citation: Ulqinaku D, and Vyshka G. (2021). Aftershock of a Vaccination Gap: The Measles Epidemics in Tirana, 2018. Mathews J Immunol Allergy. 5(1):13.

Copyright: Vyshka G, and Ulqinaku D. (C) (2021). This is an open-access article distributed under the terms of the Creative Commons Attribution License, which permits unrestricted use, distribution, and reproduction in any medium, provided the original author and source are credited. 
reporting measles outbreaks [3]. According to the same source, from January 2019 through September 2019, 1234 cases of measles have been reported in the United States and 91 reported cases in Canada, while in 2018, 372 and 28 cases were reported in the United States and Canada,

respectively [3]. With figures being relatively low for such large countries, our concerns with the outbreak in Tirana, Albania, are even more justified.

\section{MEASLES OUTBREAK IN TIRANA, 2018}

Tirana, the capital of Albania, had a similar outbreak in the midst of 2018. Officially, the previous measles epidemics dated back as remotely as of 1989. At that time, local sources were reporting a frightening figure of 168.636 cases of measles (approximating 6\% of the entire Albanian population of the period), but data probably needs confirmation. There is only one PubMed indexed paper (published 2003) reporting over measles in Albania, although local journals and periodicals have not been reticent [4]. As measles itself represents an infectious disease of major public health concern, Albania had already put in place a strict vaccination program and among other, had produced inside the country by itself 100.000 vaccinal doses already in 1977 [5].

After the last reported epidemics of 1989, reports of some disparate and isolated cases in some Albanian cities raised no worries. As such, the number of new cases registered during 2018 was of concern (1038 in total) for a single city such as Tirana. If this could be considered a 'large' outbreak, this is debatable: for example, German authors report a 'large' measles outbreak with a total figure of 614 cases in Duisburg, 2006 [6].

The graphic no. 1 describes the timeline of infected cases, with its peak during the months March-April.

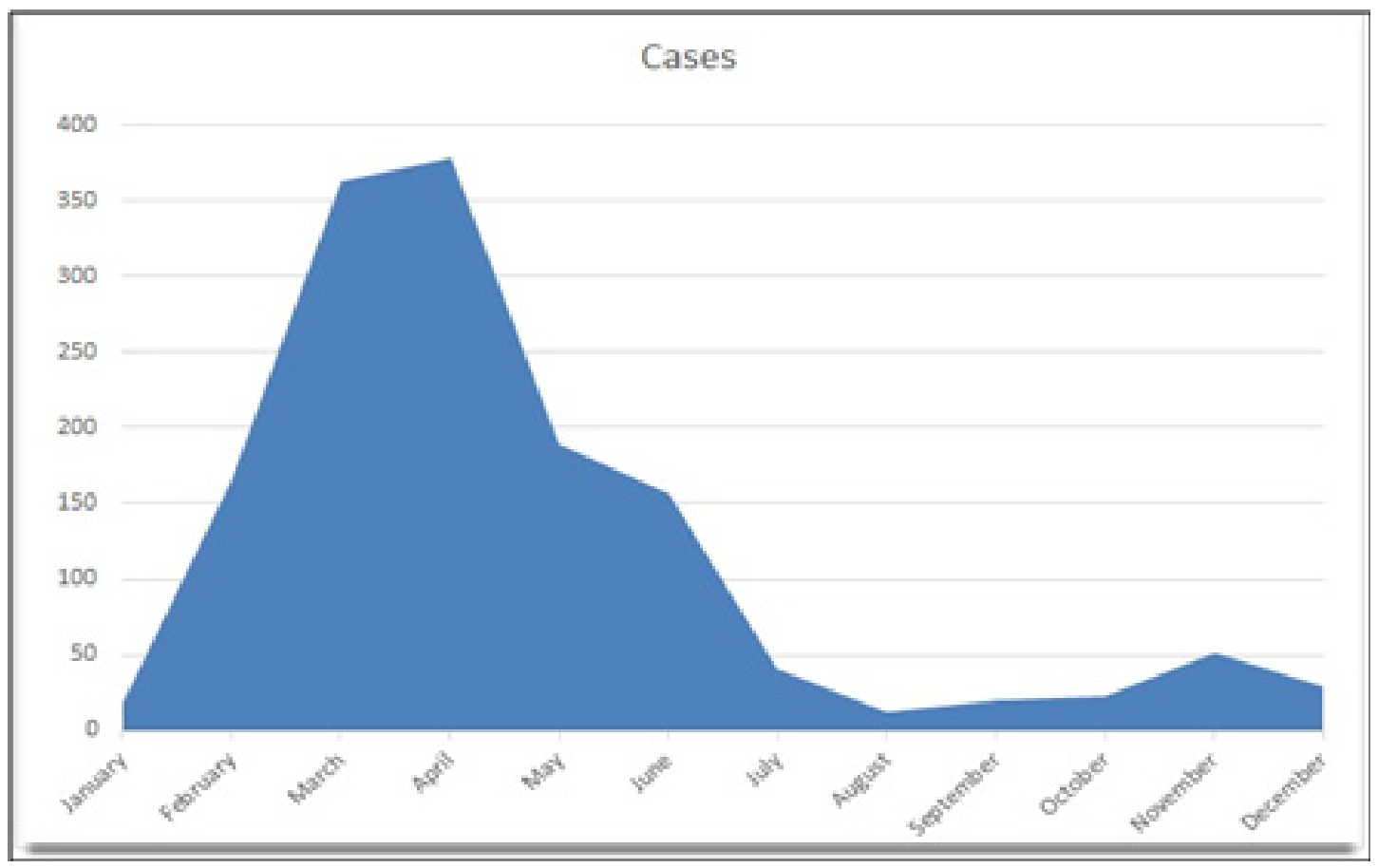

Graphic 1: Cases of measles by month; 2018 (Tirana, Albania).

Tirana had at the time a registered population of approx. half a million people, and all these 1038 new cases of measles were reported unexpectedly, with no cases in a period as long as of thirty years (1989-2018). The fact that neighbouring and other remote countries, reported similar outbreaks in the same period, might be not serendipitous [2].

A graphic analysis (graphic no. 2) of the age distribution in the registered cases showed a peak in the age group of twenty-years old people. Of note were two peaks in the most affected age groups: infants of first year of age, as well as overall among people aging between 16-30 years of life. The unequal distribution also relates to the fact that not only there was a gap of vaccination during 1997/8, but also some people might have been undervaccinated even prior to the imputed period. 


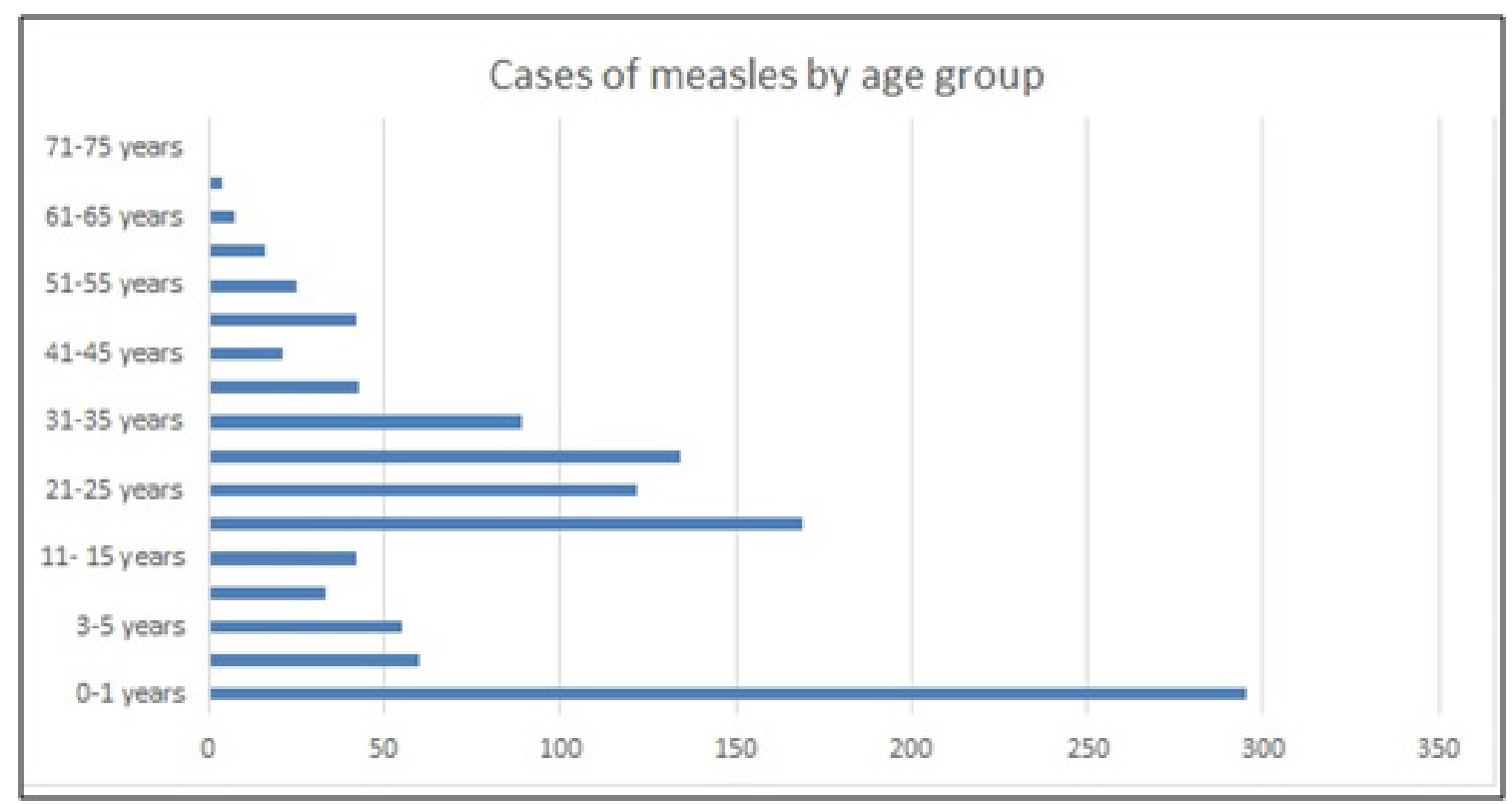

Graphic 2: age groups of measles cases in Tirana, Albania (2018).

\section{DISCUSSION}

Albania implements a strict vaccination programme with MMR (measles-mumps-rubella) since several decennia. The peak of first-year age children in the overall data regarding the epidemics of 2018 in Tirana might be related to the fact that children are vaccinated after the first year of age, counting on their protection against measles during breastfeeding period. Actually, the unvaccinated children are considered at risk [7].

Vulnerable groups have been identified from authors, here including migrants and their progeny, minority groups, as well as undervaccinated people [8-10].

The fact that children of first year of age are at still risk has pushed some authors to suggest measles vaccination to take place at the 9th month of life. In our case, undervaccination has been a major factor, with a gap in vaccination that interested precisely the age groups of 16-30 years. During the years 1997-1998 Albania has suffered a tumultuous conflict close to a civil war, and medical services were severely hit at that time; with obligatory vaccination stopping temporarily or eventually, not performed at all. Of importance is as well the geographic distribution of Tirana cases, where the overwhelming majority came from the suburban areas that are populated from internally displaced people. This group of people has migrated to the capital recently, coming from the rural areas where access to medical services has been scarce or inexistent.

\section{REFERENCES}

1. Shkurti K, Vyshka G, Velo E, Boçari A, Kokici M, et al. (2013). Imported malaria in Albania and the risk factors that could allow its reappearance. Malaria journal. 12(1):1-6.

2. Gianniki M, Siahanidou T, Botsa E, Michos A. (2021). Measles epidemicin pediatricpopulation in Greece during 2017-2018: Epidemiological, clinical characteristics and outcomes. PLoS One. 16(1):e0245512.

3. Sanyaolu A, Okorie C, Marinkovic A, Ayodele O, Abbasi AF, et al. (2019). Measles Outbreak in Unvaccinated and Partially Vaccinated Children and Adults in the United States and Canada (2018-2019): A Narrative Review of Cases. Inquiry. 56:46958019894098.

4. Bino S, Kakariqi E, Xibinaku M, Ion-Nedelcu N, Bukli $M$, et al. (2003). Measles-rubella mass immunization campaign in Albania, November 2000. J Infect Dis. 187 Suppl 1:S223-9.

5. Kakariqi E, Bifsha A. On the biological and immunogenic properties of a vaccine against measles produced in Albania in 1977. Bulletin of Tirana State University, Medical Sciences. 1979; 1: 73-80. [Article in Albanian; available at: https://ajmhs.umed.edu.al/archiveyears-1961-2016/bulletin-of-tirana-state-universitymedical-sciences-series-1-year-1979 ] (Last accessed April 17th, 2021). 
6. Wichmann O, Hellenbrand W, Sagebiel D, Santibanez S, Ahlemeyer G, et al. (2007). Large measles outbreak at a German public school, 2006. Pediatr Infect Dis J. 26(9):782-6.

7. Nelson R. (2019). US measles outbreak concentrated among unvaccinated children. Lancet Infect Dis. 19(3):248.

8. Poethko-Müller C, Ellert U, Kuhnert R, Neuhauser H, Schlaud M, et al. (2008). Vaccination coverage against measles in German-born and foreign-born children and identification of unvaccinated subgroups in Germany. Vaccine. 27(19):2563-9.
9. Schmid D, Holzmann H, Schwarz K, Kasper S, Kuo HW, et al. (2010). Measles outbreak linked to a minority group in Austria, 2008. Epidemiol Infect. 138(3):415-25.

10. Zucker JR, Rosen JB, Iwamoto M, Arciuolo RJ, Langdon-Embry M, et al. (2020). Consequences of Undervaccination - Measles Outbreak, New York City, 2018-2019. N Engl J Med. 382(11):1009-1017. 